\title{
ERRATUM
}

Correction: Acute Effect of Active and Passive Static Stretching on Elastic Modulus of the Hamstrings

Nakao G, Taniguchi K, Katayose M.

Sports Medicine International Open 2018; 02 (06):

E163-E170; DOI: 10.1055/a-0733-6957

In the above-mentioned article, the affiliations were corrected as follows:

\section{Gakuto Nakao}

1 Graduate School of Health Sciences, Sapporo Medical University, Sapporo, Japan

2 Department of Rehabilitation, Ebetsu City Hospital, Ebetsu, Japan

\section{Keigo Taniguchi}

3 Department of Physical Therapy, Sapporo Medical University, Sapporo, Japan

\section{Masaki Katayose}

3 Department of Physical Therapy, Sapporo Medical University, Sapporo, Japan 